\title{
The association of metabolic syndrome and cognitive impairment in Jidong of China: a cross-sectional study
}

Xiaohui Wang ${ }^{1 \dagger}$, Long $\mathrm{Ji}^{1+}$, Zhaoyang Tang ${ }^{1+}$, Guoyong Ding ${ }^{1}$, Xueyu Chen ${ }^{1}$, Jian LV ${ }^{1}$, Yanru Chen ${ }^{1}$ and Dong $\mathrm{Li}^{1,2^{*}}$

\begin{abstract}
Background: Metabolic syndrome (Mets) is prevalent in the general population and has been reported to be an independent risk factor for cognitive impairment. This study aimed to investigate the association of Mets with the risk of cognitive impairment.
\end{abstract}

Methods: We studied 5854 participants from the Jidong community. Cognitive function was assessed by the MiniMental State of Examination (MMSE) scale. Mets was diagnosed according to the International Diabetes Federation criteria. We used logistic regression analysis to investigate the association of metabolic syndrome with the risk of cognitive impairment.

Result: Among the 5854 adults included in the study, the age mean (SD) of age was 44 (13.57) years, and 2916 (50.34\%) were male. There was a higher (56.03\%) cognitive impairment incidence rate among participants with Mets than among those without Mets. In addition, there was a significant association between Mets and cognitive impairment (OR: 2.39, 95\% Cl: 2.00-2.86, $P<0.05)$ after adjusting for potential confounders, including age, gender, education level, marital status, smoking and alcohol consumption status. Regarding the 5 Mets components, abdominal obesity and elevated blood pressure were associated with the risk of Mets (OR: 1.36, 95\% Cl: 1.09-1.70, $P<0.001$; OR: 1.32, 95\% Cl: 1.07-1.63, $P<0.05$ ). Moreover, the strongest statistical correlation (adjusted OR: 1.86, 95\% $\mathrm{Cl}: 1.22-2.83, P<0.05)$ was found when the number of Mets components was three.

Conclusion: Our study suggested that Mets was associated with cognitive impairment and that abdominal obesity and hypertension were associated with an increased risk of cognitive impairment.

Keywords: Metabolic syndrome, Cognitive impairment, Epidemiology, Abdominal obesity, Blood pressure

\footnotetext{
* Correspondence: tsmcdongli@163.com

${ }^{+}$Xiaohui Wang, Long Ji and Zhaoyang Tang contributed equally to this work.

'Department of Epidemiology, School of Public Health, Shandong First

Medical University \& Shandong Academy of Medical Sciences, 619

Changcheng Road, Taian 271016, P.R. China

${ }^{2}$ The Second Affiliated Hospital of Shandong First Medical University, 706

Taisan Street, Taian 271000, China
}

(c) The Author(s). 2021 Open Access This article is licensed under a Creative Commons Attribution 4.0 International License, which permits use, sharing, adaptation, distribution and reproduction in any medium or format, as long as you give appropriate credit to the original author(s) and the source, provide a link to the Creative Commons licence, and indicate if changes were made. The images or other third party material in this article are included in the article's Creative Commons. licence, unless indicated otherwise in a credit line to the material. If material is not included in the article's Creative Commons licence and your intended use is not permitted by statutory regulation or exceeds the permitted use, you will need to obtain permission directly from the copyright holder. To view a copy of this licence, visit http://creativecommons.org/licenses/by/4.0/ The Creative Commons Public Domain Dedication waiver (http://creativecommons.org/publicdomain/zero/1.0/) applies to the data made available in this article, unless otherwise stated in a credit line to the data. 


\section{Background}

At present, population aging has become a serious problem in many parts of the world. A large amount of data have indicated that the proportion of older people will increase to $31 \%$ in 2050, and China will have the greatest number of older people worldwide [1]. More seriously, related diseases such as cardiovascular disease and cognitive dysfunction related to aging also significantly reduce quality of life and increase the medical burden among the elderly [2].

Cognitive impairment is a well-known disease characterized by a reduction in cognitive function beyond what was expected from normal aging. Cognitive impairment involves functions in many areas of the brain, including areas associated with memory, thinking, orientation, comprehension, calculation, learning capacity, language, judgment and daily activities [3]. Epidemiological studies have indicated that the prevalence of mild cognitive impairment (MCI) varies from $2.8-17.5 \%$ in Europe and North America and 5.4-25.0\% in different parts of China [4].

Some clinical and epidemiological studies have suggested that metabolic syndrome (Mets) plays an important role in the progression of cognitive impairment $[5,6]$. Mets is a combination of cardiovascular risk factors (abdominal obesity, dyslipidemia, hyperglycemia, and hypertension) [7]. Mets is prevalent among adults worldwide. For example, the prevalence of Mets among urban adults from 33 communities in China was 27.4\% [8], and the age-adjusted prevalence of Mets was $23 \%$ in the US general population and $30.52 \%$ in South Korea $[9,10]$.

Over the last few years, extensive research and multiple reviews have suggested that there is a link between Mets and cognitive impairment [11]. In the Sacramento Area Latino Study of Aging Study, it was reported that Mets contributes to cognitive decline, and the composite measure of Mets is associated with higher odds than individual components [12]. A recent study using a rat model of Mets found that high fructose intake resulted in disrupted insulin signaling in the brain [13]. However, previous studies reported that there was no association between Mets and cognitive impairment among older US adults [14]. In addition, a previous longitudinal study showed that metabolic syndrome was a protective factor for cognitive function decline [12, 15, 16]. The inconsistent results may be due to differences in age, education and other confounders.

Therefore, the primary aim of our study was to explore whether Mets was associated with the risk of cognitive impairment.

\section{Methods}

\section{Study population}

The cross-sectional study was based on the China suboptimal health cohort study (COACS), a longitudinal study initiated in 2013. We recruited 6653 participants from Tangshan, Hebei Province, in northern China in 2015. In addition, 799 participants were excluded due to incomplete baseline information and Mini-Mental State of Examination (MMSE) scores. Finally, 5854 individuals were included in our present study. The study was approved by the ethics committee of Jidong Oilfield Inc. [17] All participants received adequate information about the study and provided written informed consent.

\section{Physical examination and assessment of metabolic syndrome}

Diastolic blood pressure (DBP) and systolic blood pressure (SBP) were measured three times using a standard mercury sphygmomanometer by well-trained nurses. Waist circumference was measured in centimeters at the midpoint between the lowest rib margin and the top of the iliac crest at minimal respiration to the closest 0.1 $\mathrm{cm}$. Fasting plasma glucose (FPG) was measured with the hexokinase/glucose-6-phosphate dehydrogenase method. Triglycerides (TGs) were determined by enzymatic methods (Mind Bioengineering Co. Ltd. Shanghai, China). High-density lipoprotein cholesterol (HDL-C) was measured using an autoanalyzer (Hitachi 747; Hitachi, Tokyo, Japan) at the abdominal laboratory of the Staff Hospital of Jidong oilfield of Chinese National Petroleum [17].

The revised criteria of the International Diabetes Federation (IDF) criteria was used to define Mets [18]. The criteria emphasize central obesity as essential condition, that was assessed by waist circumference $(\geq 90 \mathrm{~cm}$ for Chinese men and $\geq 80 \mathrm{~cm}$ for Chinese women). Besides, the diagnostic criteria of Mets need to plus at least 2 the following cardiovascular risk factors (CVRFs). 1) raised triglycerides: $\geq 150 \mathrm{mg} / \mathrm{dl}(1.7 \mathrm{mmol} / \mathrm{l})$ or specific treatment for this lipid abnormality. 2) reduced HDLcholesterol: $<40 \mathrm{mg} / \mathrm{dL}(1.03 \mathrm{mmol} / \mathrm{l})$ in men and $<50$ $\mathrm{mg} / \mathrm{dL}(1.29 \mathrm{mmol} / \mathrm{l})$ in women or specific treatment for this lipid abnormality. 3) raised blood pressure: systolic $\geq 130 \mathrm{mmHg}$ or diastolic $\geq 85 \mathrm{mmHg}$ or treatment of previously diagnosed hypertension. 4) raised fasting plasma glucose: fasting plasma glucose $\geq 100 \mathrm{mg} / \mathrm{dL}(5.6 \mathrm{mmol} / \mathrm{l})$ or previously diagnosed type 2 diabetes.

\section{Cognitive measures and other covariates}

The MMSE was used to assess the participants' cognitive function. The MMSE consists of 30 items assessing memory, attention, language, calculation, visuospatial abilities and orientation [19]. The score ranges from 0 to 30 , and higher scores represent better cognition. In prior studies, it had been reported that the cutoff is 27 for individuals with more than 7 years of literacy $[20,21]$. The MMSE 27 cutoff had a higher sensitivity (94.9\%) and specificity (66.3\%) than the MMSE 24 cutoff [22]. 
Therefore, cognitive impairment was defined as a score less than 27 in our study.

Clinical characteristics and biochemical indicators were collected by clinical and laboratory tests. Questionnaires were used to collect information related to demographic variables and behavioral lifestyle [17]. The covariates included gender, age, education level, marital status, smoking and alcohol consumption status, WC, serum TGs, HDL-C, SBP, DBP, and FPG.

\section{Statistical analysis}

For baseline characteristics, the Kolmogorov-Smirnov test was used to evaluate the normal distribution of continuous variables. The continuous variables with normal distribution are expressed as the mean \pm standard deviation, and the categorical variables are presented as numbers (percentages). Then, continuous variables with normal distribution were compared using Student's ttest, and categorical variables were compared using chi- square test analysis. Nonnormally distributed variables were compared using nonparametric (Table 1). Next, the individuals were divided into normal and elevated or reduced groups according to the diagnostic criteria of Mets, and the t-test was used to compare the differences in MMSE scores between the two groups (Fig. 1).

Univariate and multivariate logistic regression were used to assess the association between Mets and cognitive impairment. Moreover, we used three regression models in the analysis: Model 1 was an unadjusted model, Model 2 was adjusted for age, gender, education, marital status, current smoking, and current alcohol consumption; Model 3 additionally included abdominal obesity, elevated TG, reduced HDL-C, elevated BP and elevated FPG.

Next, we inputted the number of Mets components into multivariate logistic regression to evaluate the effects of the number of abnormal Mets components on cognitive impairment. Two models were generated: one

Table 1 Baseline characteristics of the study population according to metabolic syndrome

\begin{tabular}{|c|c|c|c|c|}
\hline Characteristics & Total & MetS & Non-MetS & $P$ \\
\hline Number of subjects ( $n, \%)$ & 5854 & $2154(36.80)$ & $3700(63.20)$ & \\
\hline Age (years), mean $\pm S D$ & $43.98 \pm 13.58$ & $48.95 \pm 13.61$ & $41.07 \pm 12.69$ & $<0.001^{*}$ \\
\hline Male (n, \%) & 2944 & $1222(56.73)$ & $1722(46.55)$ & $<0.001^{*}$ \\
\hline Education level $(\mathrm{n}, \%)$ & & & & $<0.001^{*}$ \\
\hline Illiteracy/primary school & 357 & $205(9.52)$ & $152(4.11)$ & \\
\hline Middle school & 2013 & $951(44.15)$ & $1062(28.70)$ & \\
\hline College or above & 3484 & $998(46.33)$ & $2486(67.19)$ & \\
\hline Marriage (n, \%) & & & & $<0.001^{*}$ \\
\hline Single & 409 & $103(4.78)$ & $306(8.27)$ & \\
\hline Married & 5445 & $2051(95.22)$ & $3394(91.73)$ & \\
\hline Current smoking $(n, \%)$ & 1542 & $712(33.05)$ & $830(22.43)$ & $<0.001^{*}$ \\
\hline Current alcohol (n, \%) & 1852 & $784(36.40)$ & $1068(28.86)$ & $<0.001^{*}$ \\
\hline BMI $\left(\mathrm{kg} / \mathrm{m}^{2}\right)$, median (interquartile range) & $24.3(21.9,26.8)$ & $27.00(25.1,29.1)$ & $22.8(20.9,24.7)$ & $<0.001^{*}$ \\
\hline WC (cm), median (interquartile range) & $86(78,93)$ & $94(90,100)$ & $81(75,87)$ & $<0.001^{*}$ \\
\hline TGs (mmol/L), median (interquartile range) & $1.48(1.04,2.24)$ & $2.19(1.61,3.06)$ & $1.21(0.92,1.62)$ & $<0.001^{*}$ \\
\hline $\mathrm{HDL}-\mathrm{C}$ (mmol/L), median (interquartile range) & $1.22(1.06,1.40)$ & $1.12(0.98,1.28)$ & $1.27(1.12,1.46)$ & $<0.001^{*}$ \\
\hline SBP $(\mathrm{mmHg})$, median (interquartile range) & $125(113,136)$ & $136(127,148)$ & $118(110,128)$ & $<0.001^{*}$ \\
\hline DBP (mmHg), median (interquartile range) & $79(71,88)$ & $87(79,95)$ & $75(68,82)$ & $<0.001^{*}$ \\
\hline FPG (mmol/L), median (interquartile range) & $5.72(5.42,6.09)$ & $6(5.72,6.57)$ & $5.56(5.32,5.86)$ & $<0.001^{*}$ \\
\hline Elevated TGs (n, \%) & 2354 & $1556(72.24)$ & $798(21.57)$ & $<0.001^{*}$ \\
\hline Low HDL-C (n, \%) & 879 & $565(26.23)$ & $314(8.49)$ & $<0.001^{*}$ \\
\hline Elevated BP (n, \%) & 2648 & $1686(78.27)$ & $962(26.00)$ & $<0.001^{*}$ \\
\hline Elevated FPG $(n, \%)$ & 3572 & $1848(85.79)$ & $306(46.59)$ & $<0.001^{*}$ \\
\hline MMSE, mean \pm SD & $28.71 \pm 1.81$ & $28.35 \pm 2.10$ & $28.93 \pm 1.57$ & $<0.001^{*}$ \\
\hline MMSE $<27(n, \%)$ & 544 & $306(14.21)$ & $238(6.43)$ & $<0.001^{*}$ \\
\hline
\end{tabular}

sMets Metabolic syndrome, Non-Mets Non-metabolic syndrome, BMI Body mass index, WC Waist circumference, TGs Triglycerides, HDL-C High-density lipoprotein cholesterol, SBP Systolic blood pressure, DBP Diastolic blood pressure, FPG Fasting plasma glucose, MMSE Mini-mental state of examination, *: $P \leq 0.05$ : significant difference from Mets and Non-Mets 


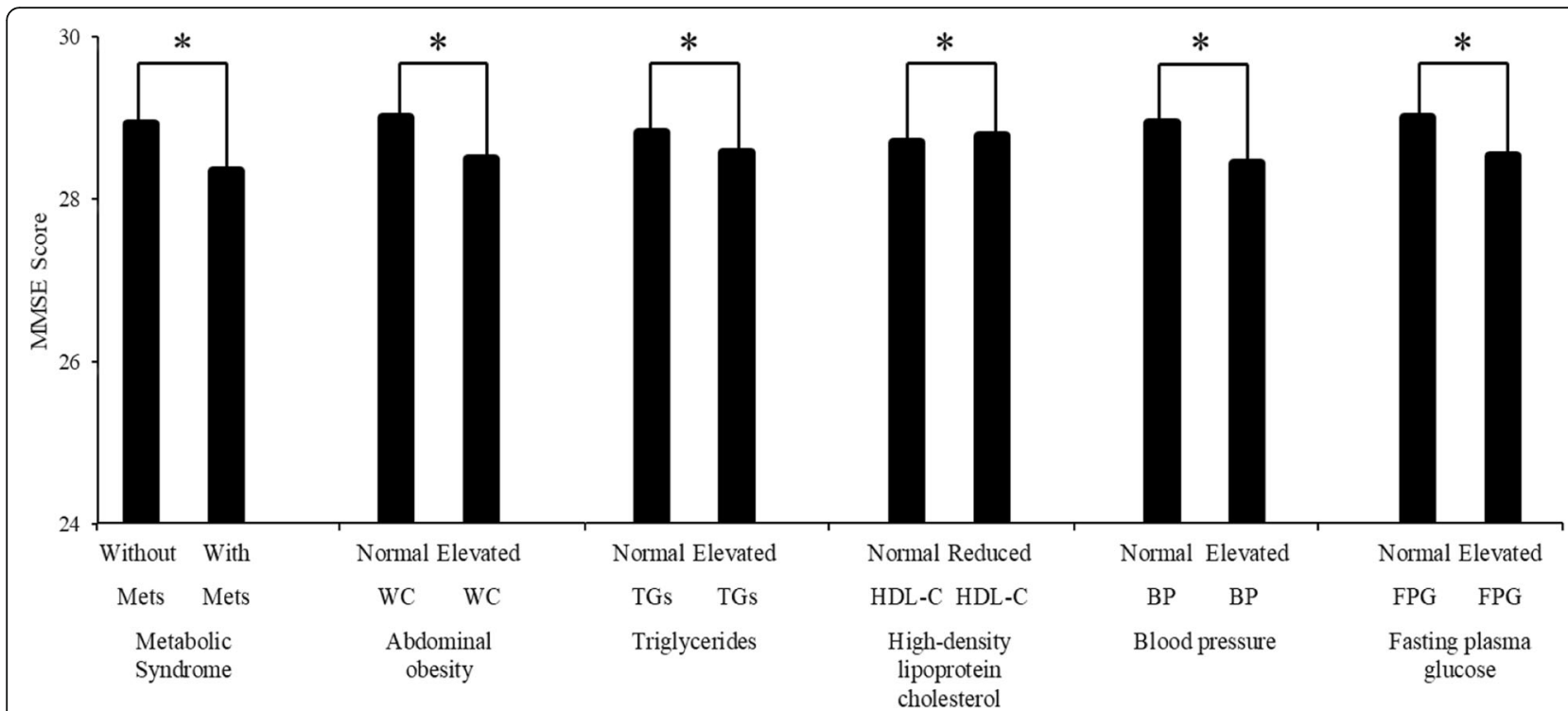

Fig. 1 Comparisons of MMSE scores between those with and without metabolic syndrome and its components. MMSE: Mini-Mental State of Examination, Mets: metabolic syndrome, Non-Mets: non-metabolic syndrome, BMI: body mass index, WC: waist circumference, TGs: triglycerides, HDL-C: high-density lipoprotein cholesterol, SBP: systolic blood pressure, DBP: diastolic blood pressure, FPG: fasting plasma glucose, WC: waist circumference, ${ }^{*}: p \leq 0.05$

made no adjustments, and the other controlled for age, gender, education, marital status, current smoking, and current alcohol consumption.

All statistical analyses were performed by SAS software, version 9.4 (SAS Institute Inc., Cary, North Carolina, USA). A $P$-value $<0.05$ was considered statistically significant.

\section{Results}

Table 1 summarizes the demographic data of 5854 participants. There were 2154 (36.80\%) participants with Mets and 3700 (63.20\%) participants without Mets. Of the 2154 participants with Mets, 1556 (72.24\%) had hypertriglyceridemia, 565 (26.23\%) had low HDL-C, 1686 (78.27\%) had high blood pressure or were diagnosed with hypertension, and 1848 (85.79\%) had high FPG or were diagnosed with hyperglycemia. The age mean \pm standard deviation of the people with Mets was $43.98 \pm 13.58$. The current study showed that older married men with smoking and alcohol abuse habits were more likely to have Mets than those without these habits $(P<0.05)$. The participants who were better educated had a lower prevalence of Mets $(P<0.05)$.

Comparisons of MMSE scores between individuals with Mets and its four components are illustrated in Fig. 1. The MMSE scores mean \pm standard deviation $(28.35 \pm 2.10)$ of participants with Mets was significantly lower than that participants without Mets $(28.93 \pm 1.57)$. People with normal WC, TGs, BP and FPG had higher MMSE scores than those with elevated WC, TGs, BP, FPG, people with normal HDL-C had lower MMSE scores than that with reduced HDL-C. All differences were statistically significant $(P<0.05)$. (The concepts of normal and elevated or reduced are consistent with the diagnostic criteria of Mets.

We further investigated the risk of cognitive impairment and Mets in different age groups (60 years) in Fig. 2. Participants with Mets had 2.41-fold odds of having cognitive impairment in the crude model (OR 2.41, 95\% CI: 2.01-2.88, $P<0.001$ ), and the association was consistent when controlling for gender, current smoking, and current alcohol consumption (OR 1.51, 95\% CI: $1.24-1.83, P<0.001)$. After the stratified analysis, the association between Mets and cognitive impairment remained significant. In the group aged $<60$ years, the unadjusted and adjusted odds ratios (ORs) and 95\% CIs were $1.812(1.39,2.36)$ and $1.374(1.04,1.82)$, respectively. In the other group (age $\geq 60$ years), the unadjusted and adjusted ORs and 95\% CIs were $1.45(1.10,1.91)$ and $1.40(1.05,1.86)$, respectively.

Figure 3 provides information on Mets, each of the 5 Mets components and the odds of cognitive impairment. Abdominal obesity, elevated triglyceride, elevated blood pressure, and elevated blood glucose were found to be significantly associated with cognitive impairment in Model 1 (all $P<0.001$; Fig. 3 ), but this association was not seen for low high-density lipoprotein.

In Model 2, abdominal obesity had an OR of 1.48 (95\% CI: $1.20-1.83, P<0.001$ ), elevated blood pressure had an OR of 1.46 (95\% CI: 1.19-1.78, $P<0.001$ ), and elevated blood glucose had an OR of 1.32 (95\% CI: $1.06-$ 1.66, $P=0.014)$. However, elevated triglyceride and 


\begin{tabular}{|c|c|c|c|}
\hline \multirow{2}{*}{ All } & OR $(95 \% \mathrm{CI})^{\mathrm{a}}$ & $2.41(2.02,2.88)$ & $\longmapsto$ \\
\hline & OR $(95 \% \mathrm{CI})^{\mathrm{b}}$ & $1.51(1.24,1.83)$ & $\mapsto \bullet$ \\
\hline \multirow{2}{*}{ Age $<60$} & OR $(95 \% \mathrm{CI})^{\mathrm{a}}$ & $1.81(1.39,2.36)$ & $\longmapsto$ \\
\hline & OR $(95 \% \mathrm{CI})^{\mathrm{b}}$ & $1.37(1.04,1.82)$ & $\longmapsto$ \\
\hline \multirow{2}{*}{ Age $\geqslant 60$} & $\mathrm{OR}(95 \% \mathrm{CI})^{\mathrm{a}}$ & $1.45(1 \cdot 10,1.91)$ & $\longmapsto$ \\
\hline & OR $(95 \% \mathrm{CI})^{\mathrm{b}}$ & $1.40(1.05,1.86)$ & $\mapsto-1$ \\
\hline
\end{tabular}

Figure 2 The odds of cognitive impairment according to metabolic syndrome in different age groups. OR, odds ratio. ${ }^{a}$ : no adjustment, ${ }^{b}$ : adjustment age, gender, education, marital status, current smoking, current drinking

reduced high-density lipoprotein were not associated with cognitive impairment (all $P>0.05$, Fig. 3 ).

In Model 3, abdominal obesity and elevated blood pressure both had statistically significant results (OR 1.36, 95\% CI: $1.09-1.70, P=0.007$; OR 1.32, 95\% CI 1.07-1.63, $P=0.010$ ). However, elevated triglyceride, reduced high-density lipoprotein and elevated blood glucose were not significantly associated with cognitive impairment (all $P>0.05$, Fig. 3).
The number of Mets components was related to cognitive impairment. Compared to the reference group with 0 components, the adjusted ORs and 95\% CI for subjects in the groups with 3 and $4 / 5$ Mets components were $1.86(1.22-2.83)$ and $1.76(1.15-$ $2.67)$, respectively. However, similar results were not found in the group with 1 and 2 Mets components $(P>0.05$; Fig. 4).

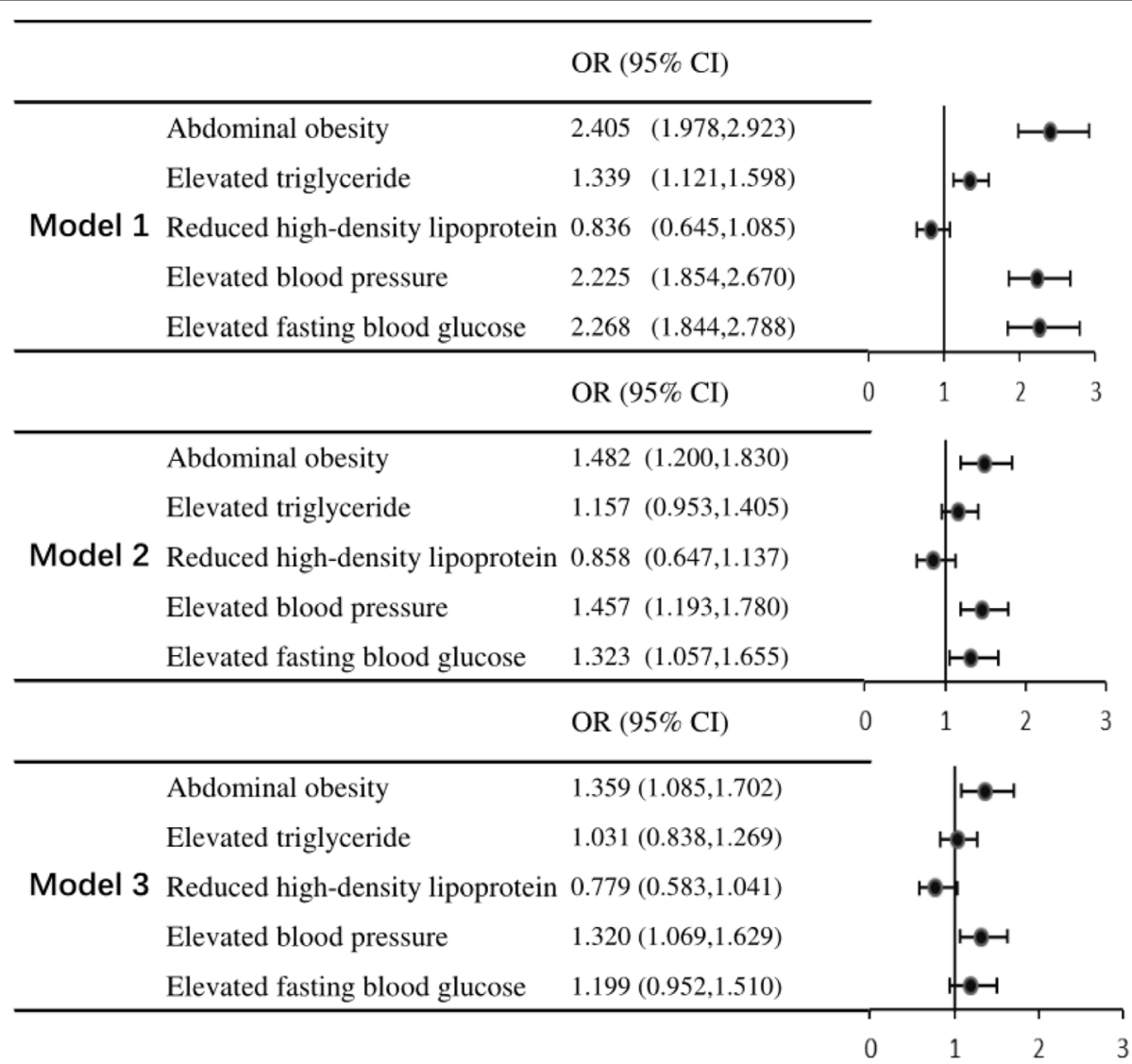

Fig. 3 Mets, each of the 5 Mets components and odds of cognitive impairment. Mets: metabolic syndrome, Non-Mets: Non-metabolic syndrome, $\mathrm{Cl}$, confidence interval, OR, odds ratio. Model 1: no adjustment, Model 2: adjustment age, gender, education, marital status, current smoking, current drinking, Model 3: model 2 plus abdominal obesity, elevated triglycerides, reduced high-density lipoprotein, elevated blood pressure, elevated glucose 


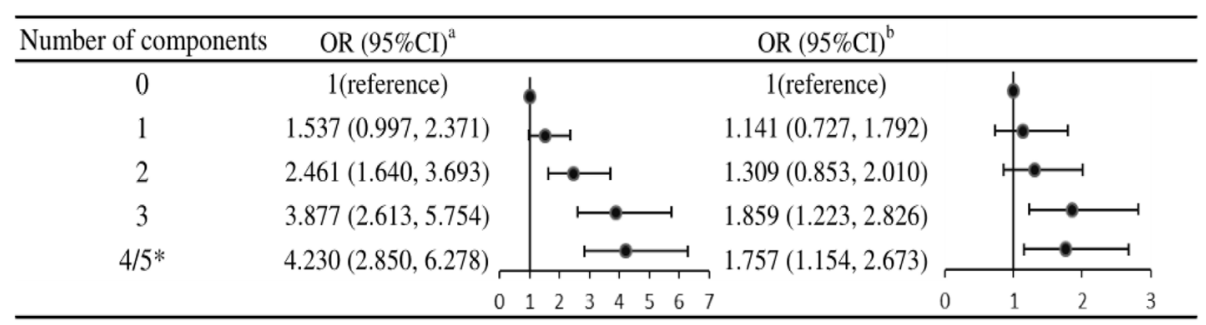

Fig. 4 Number of Mets components and odds of cognitive impairment. Mets: metabolic syndrome, Non-Mets: Non-metabolic syndrome, ${ }^{\mathrm{a}}$ :no adjustment, ${ }^{\text {b: }}$ adjusted for age, gender, education, marital status, current smoking, current drinking, Cl, confident interval, OR, odds ratio, ${ }^{*}$ due to small in each, group with 4 or 5 components were merged in this analysis

\section{Discussion}

In this community-based cross-sectional study, we found that the participants with Mets had lower MMSE scores. In addition, our results still showed a correlation between Mets and cognitive impairment after stratification by age. In this study, we observed that abdominal obesity and hypertension were independent risk factors for cognitive impairment. We also found that higher levels of education were associated with better cognitive functioning and that older age and married status were associated with worse cognitive impairment. Furthermore, we explored the relationship between Mets and cognitive impairment, and the data suggested that the strongest risk was associated with the presence of three Mets components.

According to the present study, the correlation between Mets and cognitive function is still unclear, and the conclusions are not completely consistent. Previous studies have shown that hypertension and hyperglycemia may be linked to cognitive function [23]. Age and abdominal obesity were significant risk factors for cognitive decline [16]. Studies have failed to show any association between Mets and cognitive impairment [14, 24]; however, most studies have shown that participants with metabolic syndrome are associated with increased odds of cognitive impairment [12, 15, 19, 23, 25],which is consistent with our results. Although most studies have shown that Mets and its components play roles in cognitive decline, other studies have suggested that late-life Mets has a protective effect on cognitive function [16] .

Our findings provide evidence that with the presence of abdominal obesity predicts a higher risk of cognitive impairment. The significant association was still present even after multivariable adjustments. Then, the effects of overweight on brain function may be achieved through several mechanisms. First, abdominal obesity had a stronger association with visceral adiposity than body mass index (BMI) [26] . The accumulation of visceral fat leads to metabolic disorders. Adipocytes absorb glucose, damage insulin receptor basal protein insulin signal reception, and induce insulin resistance, and insulin resistance has been defined as a potential modifiable risk factor for Alzheimer's disease (AD) [27, 28] .Second, overweight reduces serum adiponectin (APN) concentration. A lack of APN may lead to loss of neurons and synapses in the brain, increased brain $A \beta-42$ levels, deposition of amyloid- $\beta$ protein, and increased microglia and astroglia, leading to cognitive impairment [29-31] .

The current findings were consistent with previous work that demonstrated a relationship between chronic hypertension and reduced cognition. The effects of hypertension on cognitive function were mainly achieved through the following aspects.

On the one hand, hypertension leads to arterial smooth muscle hyperplasia, vascular remodeling, and the formation of atherosclerosis, which may promote reactive oxygen species production and inflammation in cerebral blood vessels. Oxidative stress and the inflammatory response are important mechanisms of cognitive impairment. On the other hand, hypertension destroys the mechanism of cerebral blood flow regulation, which compromises the clearance of brain metabolites, such as amyloid- $\beta$ and tau, favoring their accumulation. The accumulation of amyloid- $\beta$ and tau are also important mechanisms of cognitive impairment.

Previous studies have reported that type 2 diabetes mellitus (T2DM) is a risk factor for $\mathrm{AD}$, and an important mechanism may be changes in brain insulin levels [32, 33]. However, a difference between hyperglycemia and cognitive impairment was not found in our study. The percentage of participants with normal blood glucose levels was $61.02 \%$, which may partially explain why we did not observe a significant association between blood glucose and cognitive impairment. However, as shown in Fig. 2, there was a significant increase $(\mathrm{OR}=$ 1.199) in the risk of cognitive impairment in people with hyperglycemia.

This study had limitations. First, this study used a cross-sectional design, which allowed us to explore a cause-and-effect relationship. Second, the sample may not have been representative because the participants have a high education level. Third, we were unable to 
scientifically assess cognitive impairment. We measured cognitive impairment with only the MMSE, which is not a professional neurocognitive assessment. Moreover, we used 27 as the MMSE cutoff-off point rather than 24 considering the high level of education in the Jidong community.

\section{Conclusion}

In this community-based cross-sectional study, Mets was associated with the risk of cognitive impairment, and the difference was still significant in age subgroups. Our study supported abdominal obesity and hypertension as independent risk factors for cognitive impairment. Mets was associated with cognitive impairment, and preventing Mets and its components may reduce the incidence of cognitive impairment. Prospective studies on more diverse populations and the causal role of Mets in the development of cognitive impairment are needed.

\section{Abbreviations}

Mets: Metabolic syndrome; MMSE: Mini-mental state of examination; SD: Standard deviation; OR: Odds ratio; Cl: Confidence interval; MCl: Mild cognitive impairment; US: United States; COACS: China suboptimal health cohort study; DBP: Diastolic blood pressure; SBP: Systolic blood pressure; FPG: Fasting plasma glucose; TGs: Triglycerides; HDL-C: High-density lipoprotein cholesterol; CVRFs: Cardiovascular risk factors; BMI: Body mass index; AD: Alzheimer's disease; APN: Adiponectin; T2DM: Type 2 diabetes mellitus

\section{Acknowledgments}

We thank all the enrolled participants for their contributions to this study.

\section{Authors' contributions}

$X W, L J$ and $Z T$ contributed equally to this work. $D L, L J$ and $X W$ designed the study. $X C$, $J L$ and $Y C$ carried out the participant recruitment and field surveys. GD, LJ, ZT and XW conducted the data collection and statistical analysis. XW, $Z T$ and $L J$ wrote the manuscript. All authors read and approved the final manuscript.

\section{Funding}

Funding was provided by the National Natural Science Foundation of China (grant/award numbers: 81973138), the Sub-topics of National key research and development program of China (grant/award number:2017YFE0118800), the Shandong University Science and Technology Program (grant/award number: 202012050538). The project leader of 202012050538 is co-author LONG I. The funding body played a role in the design of the study, collection, interpretation of data and writing of the manuscript.

\section{Availability of data and materials}

The data used to support the findings of this study are available from the corresponding auth or upon request.

\section{Ethics approval and consent to participate}

The Human Research Ethics Committee of Shandong First Medical University (SFMU) approved this study. All procedures performed in the study involving human participants were performed in accordance with the 1964 Helsinki Declaration and its later amendments. All participants were required to sign an informed consent form before being enrolled in this study.

\section{Consent for publication}

Not applicable.

\section{Competing interests}

The authors confirm that there are no competing interests.
Received: 7 November 2020 Accepted: 21 February 2021

Published online: 04 March 2021

\section{References}

1. Panza F, D'Introno A, Colacicco AM, et al. Vascular risk and genetics of sporadic late-onset Alzheimer's disease [J]. J Neural Transm. 2004;111(1):6989.

2. Kukull WA. The growing global burden of dementia [J]. Lancet Neurol. 2006; 5(3):199-200.

3. Petersen RC. Clinical practice. Mild cognitive impairment [J]. N Engl J Med. 2011;364(23):2227-34

4. Cheng Y, Xiao S. Recent research about mild cognitive impairment in China [J]. Shanghai Arch Psychiatry. 2014;26(1):4-14.

5. Razay G, Vreugdenhil A, Wilcock G. The metabolic syndrome and Alzheimer disease [J]. Arch Neurol. 2007:64(1):93-6.

6. van de Schans VA, van den Borne SW, Strzelecka AE, et al. Interruption of Wnt signaling attenuates the onset of pressure overload-induced cardiac hypertrophy [J]. Hypertension. 2007;49(3):473-80.

7. Chowdhury MZI, Anik AM, Farhana Z, et al. Prevalence of metabolic syndrome in Bangladesh: a systematic review and meta-analysis of the studies [J]. BMC Public Health. 2018;18(1):308.

8. Song $Q B$, Zhao $Y$, Liu YQ, et al. Sex difference in the prevalence of metabolic syndrome and cardiovascular-related risk factors in urban adults from 33 communities of China: the CHPSNE study [J]. Diab Vasc Dis Res. 2015;12(3):189-98.

9. Beltrán-Sánchez H, Harhay MO, Harhay MM, et al. Prevalence and trends of metabolic syndrome in the adult U.S. population, 1999-2010[J]. J Am Coll Cardiol. 2013:62(8):697-703.

10. Lee SE, Han K, Kang YM, et al. Trends in the prevalence of metabolic syndrome and its components in South Korea: findings from the Korean National Health Insurance Service database [J]. PLoS One. 2018;13(3):e0194490.

11. Ng TP, Feng L, Nyunt MS, et al. Metabolic syndrome and cognitive decline in Chinese older adults: results from the Singapore longitudinal ageing studies [J]. Am J Geriatr Psychiatry. 2008;16(6):519-22.

12. Yaffe $K$, Haan M, Blackwell $T$, et al. Metabolic syndrome and cognitive decline in elderly Latinos: findings from the Sacramento area Latino study of aging study [J]. J Am Geriatr Soc. 2007;55(5):758-62.

13. Agrawal R, Gomez-Pinilla F. 'Metabolic syndrome' in the brain: deficiency in omega-3 fatty acid exacerbates dysfunctions in insulin receptor signaling and cognition [J]. J Physiol. 2012;590(10):2485-99.

14. Martinez-Miller EE, Kohl HW, Barlow CE, et al. Metabolic syndrome and cognitive impairment among high socioeconomic, nondemented older US adults [J]. J Am Geriatr Soc. 2019;67(7):1437-43.

15. Hishikawa N, Fukui $Y$, Sato $K$, et al. Cognitive and affective functions in Alzheimer's disease patients with metabolic syndrome [J]. Eur J Neurol. 2016;23(2):339-45

16. Liu CL, Lin MH, Peng LN, et al. Late-life metabolic syndrome prevents cognitive decline among older men aged 75 years and over: one-year prospective cohort study [J]. J Nutr Health Aging. 2013;17(6):523-6.

17. Wang Y, Ge S, Yan Y, et al. China suboptimal health cohort study: rationale, design and baseline characteristics [J]. J Transl Med. 2016;14(1):291.

18. Alberti KG, Zimmet P, Shaw J. The metabolic syndrome--a new worldwide definition [J]. Lancet (London, England). 2005;366(9491):1059-62.

19. Lee EY, Lee SJ, Kim KM, et al. Association of metabolic syndrome and 25hydroxyvitamin D with cognitive impairment among elderly Koreans [J]. Geriatr Gerontol Int. 2017;17(7):1069-75

20. Pendlebury ST, Mariz J, Bull $L$, et al. MoCA, ACE-R, and MMSE versus the National Institute of Neurological Disorders and Stroke-Canadian stroke network vascular cognitive impairment harmonization standards neuropsychological battery after TIA and stroke [J]. Stroke. 2012;43(2):464-9.

21. Tombaugh TN, Mcintyre NJ. The mini-mental state examination: a comprehensive review [J]. J Am Geriatr Soc. 1992;40(9):922-35.

22. Rosa IM, Henriques AG, Wiltfang J, et al. Putative dementia cases fluctuate as a function of mini-mental state examination cut-off points [J]. J Alzheimers Dis. 2018;61(1):157-67.

23. Goughari AS, Mazhari S, Pourrahimi AM, et al. Associations between components of metabolic syndrome and cognition in patients with schizophrenia [J]. J Psychiatr Pract. 2015;21(3):190-7.

24. Chen $B$, Jin $X$, Guo R, et al. Metabolic syndrome and cognitive performance among Chinese $>/=50$ years: a cross-sectional study with 3988 participants [J]. Metab Syndr Relat Disord. 2016;14(4):222-7. 
25. Feinkohl I, Janke J, Hadzidiakos D, et al. Associations of the metabolic syndrome and its components with cognitive impairment in older adults [J]. BMC Geriatr. 2019;19(1):77.

26. Gallagher EJ, Leroith D, Karnieli E. Insulin resistance in obesity as the underlying cause for the metabolic syndrome [J]. Mount Sinai J Med N Y. 2010;77(5):511-23.

27. Watson GS, Craft S. The role of insulin resistance in the pathogenesis of Alzheimer's disease: implications for treatment []]. CNS drugs. 2003;17(1):2745.

28. O'grady JP, Dean DC, Yang KL, et al. Elevated insulin and insulin resistance are associated with Altered Myelin in cognitively unimpaired middle-aged adults []]. Obesity (Silver Spring). 2019;27(9):1464-71.

29. Teixeira AL, Diniz BS, Campos AC, et al. Decreased levels of circulating adiponectin in mild cognitive impairment and Alzheimer's disease [J]. NeuroMolecular Med. 2013;15(1):115-21.

30. Veronese N, Facchini S, Stubbs B, et al. Weight loss is associated with improvements in cognitive function among overweight and obese people: a systematic review and meta-analysis [J]. Neurosci Biobehav Rev. 2017;72: 87-94.

31. Ng RC, Cheng OY, Jian M, et al. Chronic adiponectin deficiency leads to Alzheimer's disease-like cognitive impairments and pathologies through AMPK inactivation and cerebral insulin resistance in aged mice [J]. Mol Neurodegener. 2016;11(1):71.

32. Ríos JA, Cisternas $P$, Arrese $M$, et al. Is Alzheimer's disease related to metabolic syndrome? A Wnt signaling conundrum [J]. Prog Neurobiol. 2014; 121(104):125-46.

33. Adeghate E, Donáth T, Adem A. Alzheimer disease and diabetes mellitus: do they have anything in common [J]. Curr Alzheimer Res. 2013;10(6):609-17.

\section{Publisher's Note}

Springer Nature remains neutral with regard to jurisdictional claims in published maps and institutional affiliations.

Ready to submit your research? Choose BMC and benefit from:

- fast, convenient online submission

- thorough peer review by experienced researchers in your field

- rapid publication on acceptance

- support for research data, including large and complex data types

- gold Open Access which fosters wider collaboration and increased citations

- maximum visibility for your research: over $100 \mathrm{M}$ website views per year

At $\mathrm{BMC}$, research is always in progress.

Learn more biomedcentral.com/submissions 